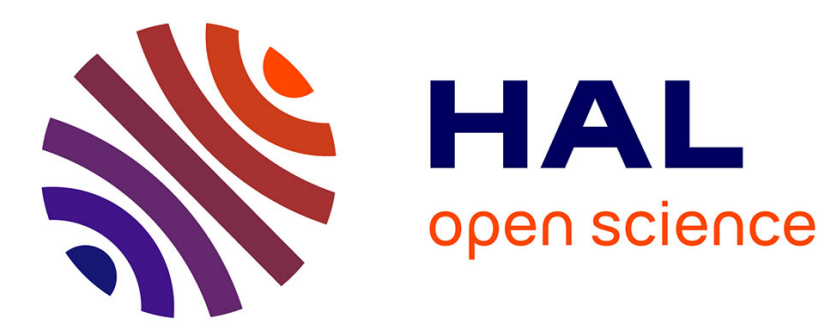

\title{
Smart Drivers for Online Diagnosis of Electrostatic MEMS Actuators
}

\author{
Norbert Dumas, Laurent Latorre, Frédérick Mailly, Pascal Nouet
}

\section{To cite this version:}

Norbert Dumas, Laurent Latorre, Frédérick Mailly, Pascal Nouet. Smart Drivers for Online Diagnosis of Electrostatic MEMS Actuators. IMS3TW'10: 16th IEEE International Mixed-Signals, Sensors and Systems Test Workshop, La Grande Motte, Montpellier, France. pp.N/A. lirmm-00494515

\section{HAL Id: lirmm-00494515 https://hal-lirmm.ccsd.cnrs.fr/lirmm-00494515}

Submitted on 23 Jun 2010

HAL is a multi-disciplinary open access archive for the deposit and dissemination of scientific research documents, whether they are published or not. The documents may come from teaching and research institutions in France or abroad, or from public or private research centers.
L'archive ouverte pluridisciplinaire HAL, est destinée au dépôt et à la diffusion de documents scientifiques de niveau recherche, publiés ou non, émanant des établissements d'enseignement et de recherche français ou étrangers, des laboratoires publics ou privés. 


\title{
Smart Drivers for Online Diagnosis of Electrostatic MEMS Actuators
}

\author{
N. Dumas, L. Latorre, F. Mailly, and P. Nouet, Member, IEEE
}

\begin{abstract}
This paper introduces the design of High-Voltage CMOS drivers for Electrostatic MEMS switches. In order to perform online diagnosis, the proposed architecture implements a dedicated circuitry that can detect the pull-in event. This way, stuck or broken switches are identified during operation. The pull-in event corresponds to a rapid change in the actuation capacitance thus producing a current peak during actuation. The idea is therefore to measure the charging current, using a differential method that cancels the effects of any parallel parasitic capacitance.
\end{abstract}

Index Terms- MEMS, CMOS, Electrostatic Actuator, Switch, Diagnosis

\section{INTRODUCTION}

A FTER years of continuous development and improvement, MEMS based electrostatic switches have become quite popular. They are now considered for various applications related to RF telecommunications where they advantageously replace the traditional PIN diodes as switching components, due to their unbeatable low insertion loss. Although much works have been done to improve MEMS switches reliability in the past years, the design of high addedvalue systems integrating such devices is not considered without some level of robustness against possible MEMS failure. This study is part of a project that target the design of reflect arrays antennas for telecom applications. In this application, thousands of MEMS switches are embedded into RF cells to open or short RF paths so that a continuous phase shift is achieved between incident and reflected waves. As different switches configurations may achieve the same phase shift, the architecture features an intrinsic redundancy so that alternate RF path may be used if non-working MEMS are well identified [1]. Moreover, a huge quantity of MEMS is used in a small surface, so that the control and driving circuitry, including the diagnosis functionality, must be integrated into small ASICs.

The proposed diagnosis approach is non-invasive from a $\mathrm{RF}$ point of view since RF path is not directly altered. It is based on the monitoring of the actuation current as used in [2] or [3] and thus only concerns the actuation circuitry. Note that the quality of the contact (either resistive or capacitive) is not monitored using this method.

\section{Switch MOdELING \& SimUlation}

\section{A. Device Architecture}

This study addresses generic MEMS actuators or switches. It is only assumed that the actuation is based on electrostatic force in a parallel plate capacitor. The contact nature can be resistive or capacitive, using both serial or shunt configuration. For the simulations however, the pseudorealistic case sketched in Fig. 1 is considered. It represents basic capacitive shunt architecture, which is very common in RF applications. The function of the switch is to connect two planes together in order to provide a path for the RF waves into the patch. The moving part of the switch is a metal cantilever beam attached (both mechanically and electrically) to a ground plane. It is actuated by means of a large bottom electrode which is positively biased. When actuated, the cantilever beam lands on a thin dielectric layer thus connecting the two planes through the capacitor $\mathrm{C}_{\mathrm{RF}}$. Since the thicknesses of the planes is greater than the thickness of the actuation electrode, the air gap between the cantilever and the actuation electrode never closes, preventing the device from known reliability issues associated with high electric fields in dielectrics. The price to pay is a higher actuation voltage and a lower ratio $C_{\text {Act,up }} / C_{\text {Act,down }}$ which makes the use of $C_{A c t}$ measurement more challenging for the diagnosis, as it will be developed later on in this paper. In addition, the parasitic capacitor $C_{P}$ that results from the routing of the actuation electrode makes the measurement even more complicated.

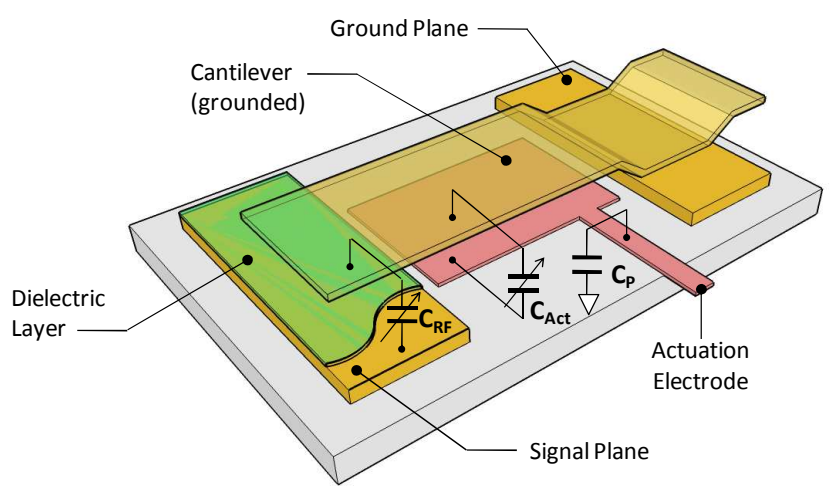

Figure 1. Structure of the MEMS switch under consideration. 


\section{B. Modeling}

According to Fig. 2, the switch model is based on a springmass-damper system (kMD), translating along the vertical axis. The mass displacement $z$ is controlled by an electrostatic actuator made of two parallel plates of surface $S_{A}$, separated by an initial gap $g_{0}$. Assuming that the bottom electrode is covered by a dielectric layer of thickness $t_{o x}$ and of relative permittivity $\varepsilon_{r}$, the resulting capacitance between the two electrodes is given by:

$$
C_{A c t}=\frac{\varepsilon_{0} S_{A}}{g_{e f f}}
$$

where $g_{\text {eff }}$ is the effective gap calculated by taking into account the two serial capacitances:

$$
g_{e f f}=z-t_{o x}+\frac{t_{o x}}{\varepsilon_{r}}
$$

The switch travel is practically hard-limited by the signal plane height. In order avoid convergence troubles within the simulator a squeeze-film damping effect is modeled into a socalled limiter block. This somehow makes the landing of the beam onto the finger surface smoother. Within a short range above the finger surface, the limiter acts in force-source mode and the squeeze film effect is modeled by an additional damping force given by:

$$
F_{L}=\alpha\left(\frac{\eta S_{F}}{z-s t o p}\right) \dot{z}
$$

where $\eta$ represent the air viscosity in Pas.s, $S_{F}$ is the overlap surface between the bridge and the finger and $\alpha$ an exaggeration factor (set to 1 by default). If the conditions $z \approx$ stop and $\dot{Z} \approx 0$ are reached, the limiter switches to position-source mode and holds the bridge at $z=$ stop as long as the electrostatic actuator forces the cantilever down.

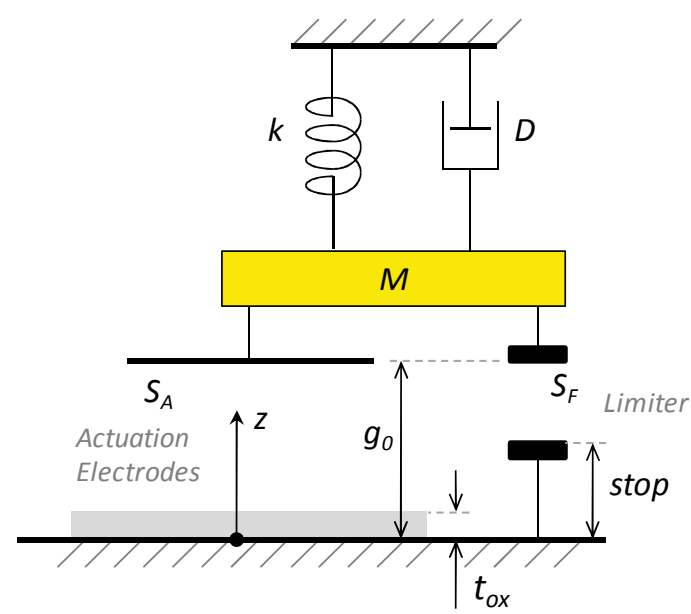

Figure 2. Switch model
Fig. 3 shows the straightforward implementation of this model under Cadence ${ }^{\circledR}$. Each part of the model is described using the proprietary Verilog-A language. The discipline kinematic is used to represent the $z$ node. Using this discipline, the "across" quantity (same as voltage) represent the vertical position of the bridge, while the "through" quantity (same as current) represents the forces. Forces equilibrium of on node $\mathrm{z}$ is therefore a direct application of Kirchhoff's circuit laws. Table I summarizes the model parameters used in following simulations for further reference.

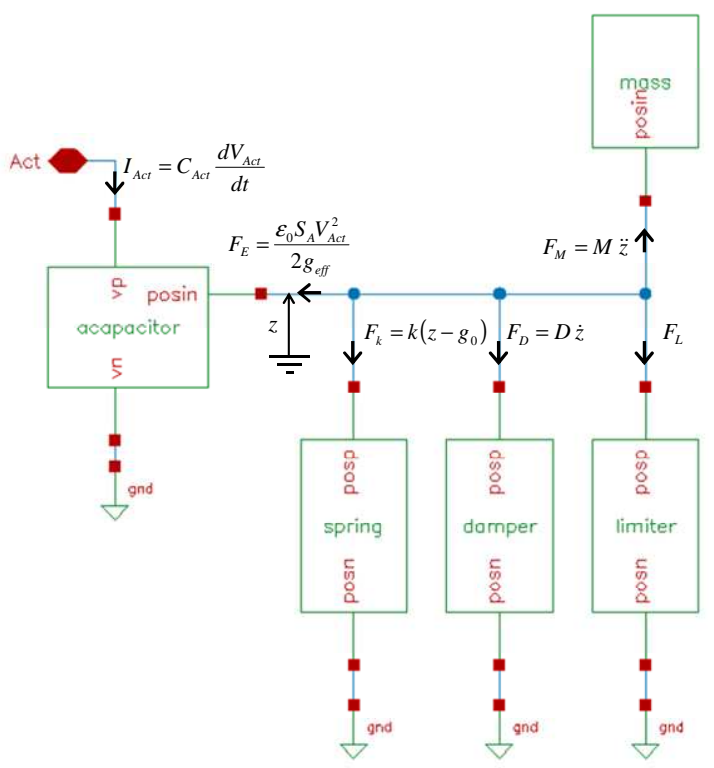

Figure 3. Model implementation within Cadence ${ }^{\circledR}$.

\begin{tabular}{|c|c|c|c|}
\hline Cell & Symbol & Quantity & Value \\
\hline \multirow{4}{*}{ 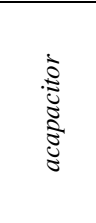 } & $S_{A}$ & $\begin{array}{l}\text { Actuation Electrode } \\
\text { Surface }\end{array}$ & $100 \times 10^{-9} \mathrm{~m}^{2}$ \\
\hline & $\varepsilon_{0}$ & Abs. Permittivity & $8.85 \times 10^{-12}$ F.m ${ }^{-1}$ \\
\hline & $\varepsilon_{r}$ & $\begin{array}{l}\text { Bottom dielectric } \\
\text { relative permittivity }\end{array}$ & 3.9 \\
\hline & $t_{o x}$ & $\begin{array}{l}\text { Bottom dielectric } \\
\text { thickness }\end{array}$ & $1 \mu \mathrm{m}$ \\
\hline \multirow{2}{*}{ spring } & $k$ & Spring Constant & $0.5 \mathrm{~N} \cdot \mathrm{m}^{-1}$ \\
\hline & $d_{0}$ & Initial gap & $17 \mu \mathrm{m}$ \\
\hline mass & $M$ & Mass & $1 \times 10^{-10} \mathrm{~kg}$ \\
\hline damper & $D$ & Damping Factor & $5 \times 10^{-6} \mathrm{~N} \cdot \mathrm{m}^{-1} \mathrm{~s}^{2}$ \\
\hline \multirow{4}{*}{ 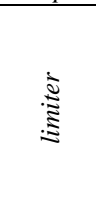 } & sflayer & $\begin{array}{l}\text { Gap for squeeze- } \\
\text { film damping action }\end{array}$ & $0.5 \mu \mathrm{m}$ \\
\hline & $\eta$ & Air viscosity & $18 \times 10^{-6}$ Pas.s \\
\hline & $S_{F}$ & $\begin{array}{l}\text { Finger overlap } \\
\text { surface }\end{array}$ & $25 \times 10^{-9} \mathrm{~m}^{2}$ \\
\hline & stop & Finger height & $2.65 \mu \mathrm{m}$ \\
\hline
\end{tabular}

TABLE I

ELECTROSTATIC SWITCH MODEL PARAMETERS 


\section{SMART DRIVER DESIGN}

The primary function of the driver is to provide the actuation voltage $\mathrm{V}_{\text {Act }}$ that is close to $46 \mathrm{~V}$ in our case. For this, the High-Voltage (HV) $0.35 \mu \mathrm{m}$ CMOS technology (h34b4c3) from Austria MicroSystems (AMS) was chosen to develop the integration of such drivers in the context of a multiple channels chip. The design of the basic driver stage is addressed first. Then two approaches are proposed to upgrade the driving circuitry with a diagnosis capability.

\section{A. High-Voltage Driver}

The challenge when designing a HV driver is to combine the low voltage level of the control circuitry (typically $3.3 \mathrm{~V}$ ) with the higher voltages that bias the output stage $(50 \mathrm{~V})$. In this study, it was assumed that only two external supply voltages were available: a low $3.3 \mathrm{~V}$ and a high voltage supply that may vary from $20 \mathrm{~V}$ to $50 \mathrm{~V}$ to adapt various switch pull-in conditions.

The proposed driver is shown in Fig. 4. It is based on a pair of $\mathrm{HV}$ transistors $\mathrm{Q}_{3}$ and $\mathrm{Q}_{4}$. In this configuration, the gate of $\mathrm{Q}_{4}$ can be directly driven by the low-voltage levels $(0-3.3 \mathrm{~V})$. The gate of $\mathrm{Q}_{3}$ must be driven between $\mathrm{V}_{\mathrm{CC}}$ and a lower voltage that turns $\mathrm{Q}_{3}$ on, while keeping the magnitude of $\mathrm{V}_{\mathrm{GS} 3}$ within $20 \mathrm{~V}$ which is a technological constraint. This condition is ensured by the level-shifter stage made of $\mathrm{Q}_{1}, \mathrm{Q}_{2}$ and $\mathrm{V}_{\mathrm{b}}$. When input is $0, Q_{2}$ is off. There is no current flowing in the level-shifter and $\mathrm{V}_{\mathrm{GS} 3}$ is 0 . When input is $3.3 \mathrm{~V}, \mathrm{Q}_{2}$ is turned on. The current flowing in the level shifter is regulated by the voltage drop across $\mathrm{R}_{1}$ so that $\mathrm{V}_{\mathrm{GS} 1} \approx-\mathrm{V}_{\mathrm{tp}} \approx-1,7 \mathrm{~V}$. The voltage drop $\mathrm{V}_{\mathrm{b}}$ is designed to be about $10 \mathrm{~V}$ (50\% of the $20 \mathrm{~V}$ limit). It is implemented by means of few diode-mounted transistors in series, biased by a resistive load tied to the ground. Doing-so ensures that $V_{b}$ stays constant for a wide range of supply voltage. It finally comes that the voltage on the gate of $\mathrm{Q}_{3}$ in on-state is close to $\mathrm{V}_{\mathrm{CC}}-\mathrm{V}_{\mathrm{b}}+\mathrm{V}_{\mathrm{tp}} \approx 41.7 \mathrm{~V}$. Note that the static consumption of the driver is here mainly determined by $\mathrm{R}_{1}$ whose value is practically restricted by its cost in term of silicon area.

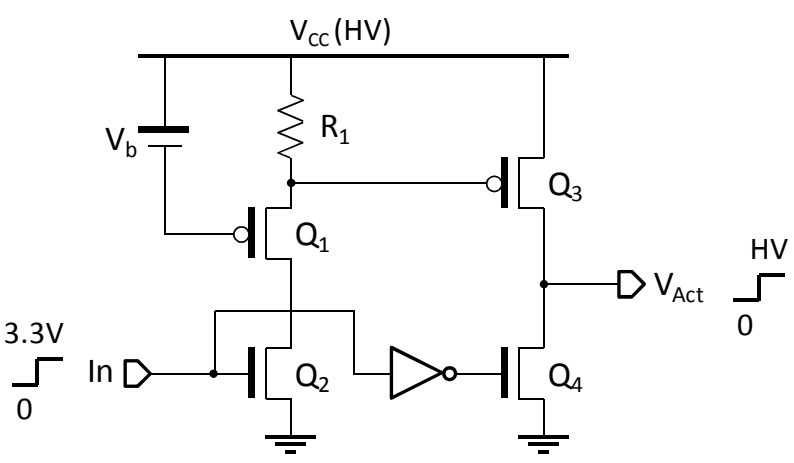

Figure 4. Structure of the HV driver.

\section{B. Diagnosis Principles}

Fig. 5 illustrates the transient response of the switch to an actuation pulse. It is obtained by the simulation of the HV driver previously described together with the switch model and a RC network $\left(R_{s e r}=1 \mathrm{M} \Omega\right.$ and $\left.C_{p a r}=5 \mathrm{pf}\right)$ representing a rather bad case for the routing. As mentioned before, the diagnosis approach must not interfere with the RF path. Fortunately, the switch pull-in produces a distinctive actuation current profile which is a good start for an investigation.

The driver output is turned on at $\mathrm{t}_{0}=0$, providing an almost instant and stable $40 \mathrm{~V}$ voltage for $V_{A c t}$. The transient current then exhibits a first peak corresponding to the charge through $R_{\text {ser }}$ of the capacitance $\mathrm{C}_{\mathrm{par}}+\mathrm{C}_{\mathrm{Act}, \mathrm{up}}$. The charge is almost completed when $V_{\text {cap }}$ reaches its final value of $40 \mathrm{~V}\left(\mathrm{t}_{1} \approx 30 \mu \mathrm{s}\right)$ and before the cantilever starts its travel. At $t_{2}=75 \mu \mathrm{s}$, the cantilever gets close to its lower position producing a fast increase of $C_{A c t}$. This causes a new small current overshoot corresponding to the charge of $\Delta C_{A c t}=C_{A c t, d o w n}-C_{A c t, u p}$. Note that during this charge, the $V_{C a p}$ voltage exhibits a small notch that can be neglected. Finally, all signals become stable after $\mathrm{t}_{\mathrm{end}}=150 \mu \mathrm{s}$.

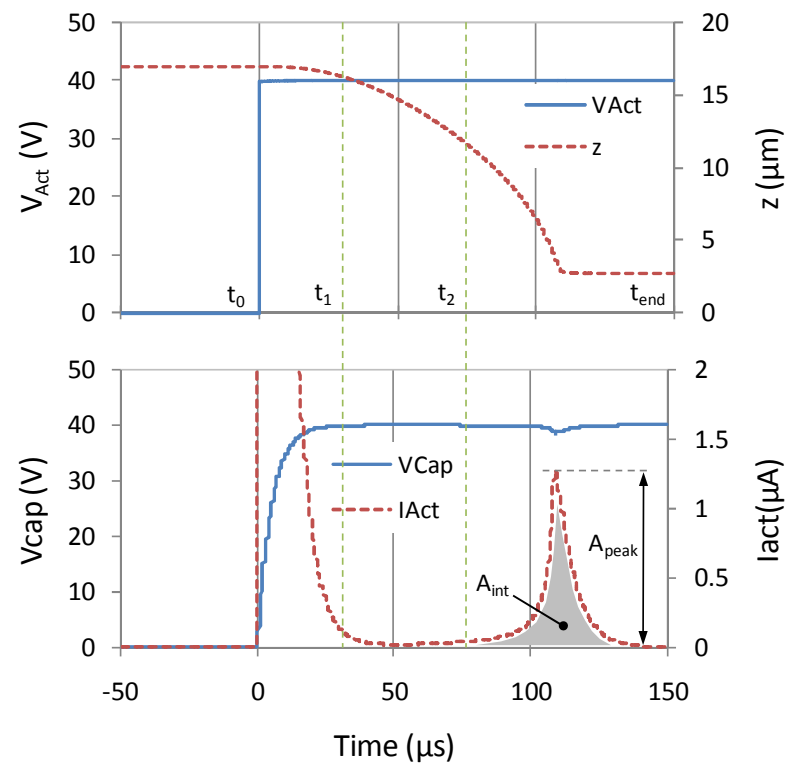

Figure 5. Transient simulation of an actuation event.

Since the second current peak will not occur in the case of broken or stuck MEMS, it makes sense to develop a diagnostic strategy based on the measurement of the actuation current. An obvious method would be the simple measurement of the amplitude of the second overshoot $\left(\mathrm{A}_{\text {peak }}\right)$, however the peak amplitude strongly depends on the routing parameters $\left(\mathrm{R}_{\mathrm{ser}}\right.$, $\mathrm{C}_{\mathrm{par}}$ ) that may vary in a significant range. This is shown by the simulation in Fig. 6.a, where $A_{\text {peak }}$ varies by $120 \%$ with the routing parameters. On the other hand, the amount of electric charges transferred in the electrostatic actuator when $C_{A c t}$ changes from $C_{A c t, u p}$ to $C_{A c t, d o w n}$ is relatively insensitive to 
routing parameters. Fig. 6.b shows that the current integral $\left(\mathrm{A}_{\mathrm{int}}\right)$ measured within the time window corresponding to the second current peak only varies by $4 \%$ for the same routing parameters range. As a consequence, a diagnostic approach based on the actuation current integration seems more appropriate in our case.

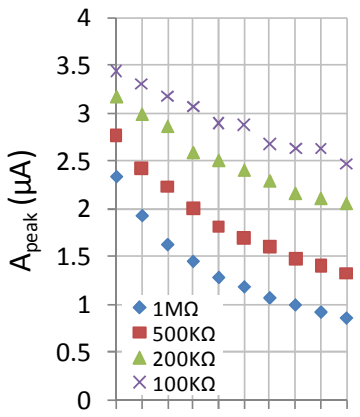

12345678910

$\mathrm{C}_{\text {par }}(\mathrm{pF})$

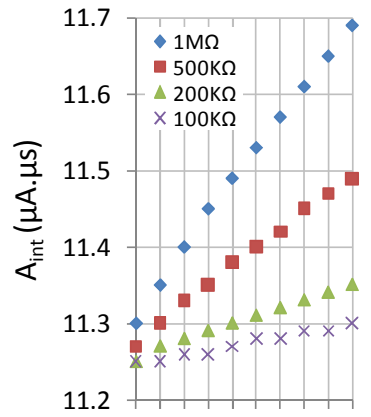

12345678910

$\mathrm{C}_{\mathrm{par}}(\mathrm{pF})$
Figure 6. a-(left) Variation in amplitude of the second actuation current peak as a function of routing parameters. b-(right) Variation of the actuation current integral during the second peak.

The total amount of charges stored in $C_{p a r}$ and $C_{A c t}$ during the whole actuation process does not depend on $R_{\text {res }}$ and writes:

$$
q(t)=V_{A c t}(t)\left(C_{p a r}+C_{A c t}(t)\right)
$$

Looking at the actuation current, we have:

$$
\begin{gathered}
i_{A c t}(t)=\frac{d q(t)}{d t}= \\
\left(C_{p a r}+C_{A c t}(t)\right) \frac{\partial\left(V_{A c t}(t)\right)}{\partial t}+V_{A c t}(t) \frac{\partial\left(C_{A c t}(t)\right)}{\partial t}
\end{gathered}
$$

The second spike of current is caused by the second term of Eq. 5 when the actuation voltage is constant and the capacitance changes. As the derivative of the actuation voltage is null during the second spike, the integration of the actuation current from the beginning of the second spike $t_{2}$ to $t_{\text {end }}$ results in:

$$
\int_{t_{2}}^{t_{\text {end }}} i_{A c t} d t=\int_{t_{2}}^{t_{\text {end }}} V_{\text {Act,end }} \frac{d\left(C_{A c t}(t)\right)}{d t} d t=V_{A c t, \text { end }} \Delta C_{A c t}(6)
$$

With:

$\Delta C_{A c t}=C_{A c t, \text { end }}-C_{A c t, 0}=C_{A c t, \text { down }}-C_{A c t, u p}$

Eq. 6 clearly expresses that the result of integrating the actuation current during the second spike does not depend on the parasitic capacitance. However, it is valid only if the two spikes can be well separated. It implies that the time constant of the first spike, i.e. $R_{\text {res }} \times C_{\text {par }}$, should be much lower than the time response of the switch.

\section{Smart-Driver Architecture \#1}

The first improved version of the HV driver presented above is depicted in Fig. 7. In this circuit, the actuation current is mirrored into the capacitor $C_{i n t}$ so that the voltage across $C_{i n t}$ represents the integration of $I_{A c t}$. A cascode mirror configuration, with a copy ratio $\beta=W_{Q 6,08} / W_{Q 5,07}$, has been preferred to improve the $\mathrm{V}_{\mathrm{DS}}$ matching of the pair $\mathrm{Q}_{5} / \mathrm{Q}_{6}$ and thus guaranty a better accuracy of the copy. Transistor $\mathrm{Q}_{9}$ is used to initialize the integrator state and then start the integration process upon falling edge of the Reset control input. Note that the gate $\mathrm{Q}_{9}$ is associated with dummy transistors (not represented) to minimize integration errors due to charge injection.

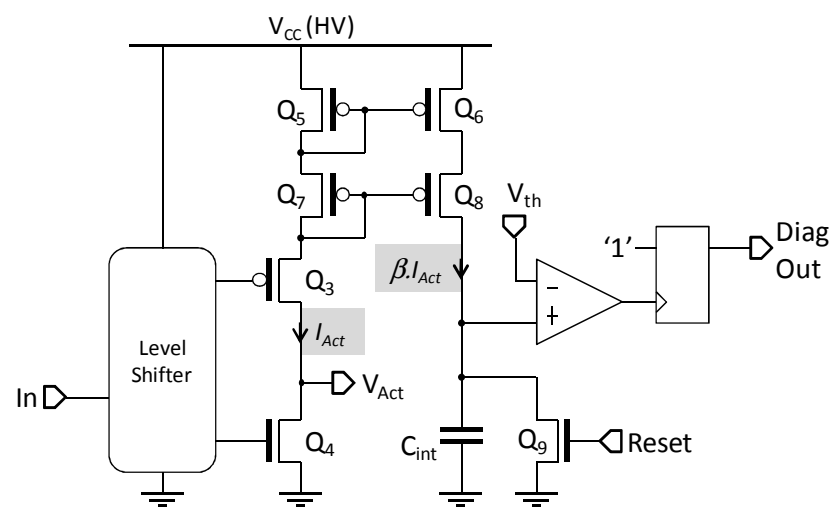

Figure 7. Structure of the HV driver with Actuation Current integrator.

If the voltage across $C_{\text {int }}$ reaches $V_{t h}$, a ' 1 ' is stored in the latch meaning a successful commutation of the switch, otherwise the diagnosis output is ' 0 '. The independent control of the Reset pin allows the integration process to start anytime.

Two strategies have been investigated: If the MEMS time constant is short, or uncertain, the integration may start from $\mathrm{t}_{0}$. In that case, the total actuation current is summed up in the integrator and the result depends strongly on the parasitic capacitance. Therefore, the parasitic capacitance should be known in order to make the diagnosis. Otherwise, if the MEMS time constant is long and well characterized, the integration may start from $t_{2}$ so that only the current associated with the pull-in event is accumulated. This second method has been validated with results reported in [3].

\section{Smart-Driver Architecture \#2}

The previously proposed method requires the good knowledge of the switch dynamic behavior, which must feature a slow-enough, predictable and stable time response to detach the pull-in from the charge of the parasitic capacitance. If these conditions are not met, a different approach to eliminate the effects of the routing parameters is necessary. A possible solution is proposed with the architecture shown in Fig. 8. 


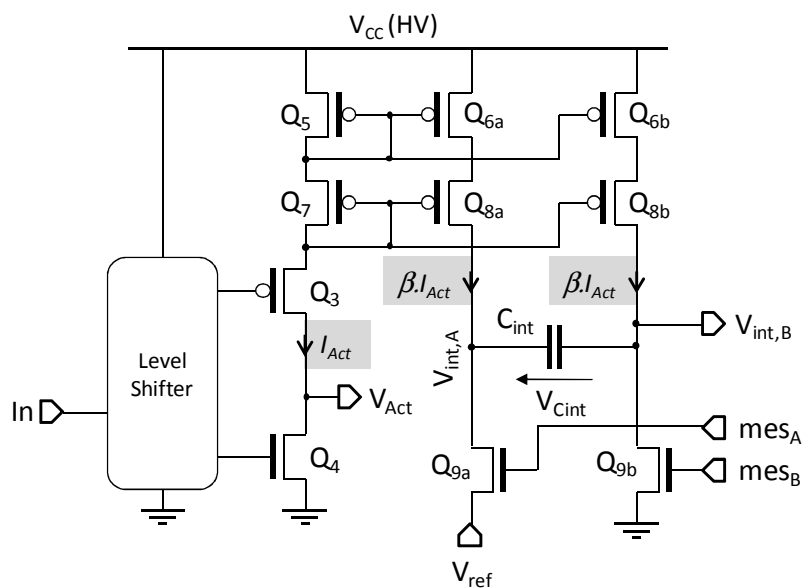

Figure 8. Structure of the HV driver with a Differential Actuation Current integrator.

The measurement sequence start with an initialization of the charge in $\mathrm{C}_{\text {int }}$ by turning on both $\mathrm{Q}_{9 \mathrm{a}}$ and $\mathrm{Q}_{9 \mathrm{~b}}$ so that $\mathrm{V}_{\mathrm{Cint}}=$ $\mathrm{V}_{\text {ref. }}$. During phase \#1, $\mathrm{V}_{\mathrm{cc}}$ is set to provide only half of the final actuation voltage $V_{A c t}$ at the driver output, $\mathrm{Q}_{9 \mathrm{~b}}$ is turned off and the driver is activated ( $\mathrm{In}={ }^{\prime} 1$ '). The actuation current is summed up in $\mathrm{C}_{\text {int }}$. After the integration time, and assuming that the driver output is below the pull-in voltage the voltage, $\mathrm{V}_{\mathrm{int}, \mathrm{B}}$ is given by:

$$
V_{\text {int }, B}=\frac{\beta}{C_{\text {int }}} \frac{V_{A c t}}{2}\left(C_{\text {par }}+C_{\text {Act }, \text { up }}\right)
$$

During phase \#2, the transistor $\mathrm{Q}_{9 \mathrm{a}}$ is turned off, and $\mathrm{Q}_{9 \mathrm{~b}}$ is closed to connect the node $\mathrm{V}_{\text {int, } \mathrm{B}}$ to ground. At this moment, the voltage $\mathrm{V}_{\text {int,A } \mathrm{A}}$ is:

$$
V_{\text {int }, A}=V_{\text {ref }}-V_{\text {int }, B}
$$

$V_{C C}$ is now adjusted to make the driver outputs $V_{A c t}$ so that another $V_{A c t} / 2$ voltage step is applied on the switch. The pull-in occurs and then after another integration period, $V_{\text {int }, A}$ becomes:

$$
\begin{aligned}
& V_{\text {int }, A}=\left(V_{\text {ref }}-V_{\text {int }, B}\right)+\frac{\beta}{C_{\text {int }}} \frac{V_{\text {Act }}}{2}\left(C_{\text {par }}+C_{\text {Act }, \text { down }}\right) \\
& V_{\text {int }, A}=V_{\text {ref }}+\frac{\beta}{C_{\text {int }}} \frac{V_{\text {Act }}}{2} \Delta C_{A c t}
\end{aligned}
$$

In summary, the amount of current charging $C_{p a r}$ is summed up in $C_{i n t}$ during the first $V_{A c t} / 2$ step, and then subtracted during the second $V_{A c t} / 2$ step, leaving the integrator output with an image of the $\Delta C_{A c t}$ charge only.

The complete sequence shown in Fig. 9 with no MEMS connected to the driver. Because $\Delta C_{A c t}=0$ in this case, the diagnosis output $\left(\mathrm{V}_{\text {int, } \mathrm{A}}\right)$ is $\mathrm{V}_{\text {ref }}$ at the end. The simulation is performed with $\mathrm{R}_{\mathrm{ser}}=1 \mathrm{M} \Omega, \mathrm{C}_{\mathrm{par}}=10 \mathrm{pF}, \beta=1 / 16$ and $\mathrm{C}_{\mathrm{int}}=15 \mathrm{pF}$. With $\mathrm{V}_{\mathrm{cc}}=40 \mathrm{~V}$, the actuation voltage is roughly $\mathrm{V}_{\mathrm{act}}=37.2 \mathrm{~V}$. According to Eq. (7), the voltage $V_{\text {int,B }}$ after phase \#1 reaches $775 \mathrm{mV}$, which is verified by the simulation.

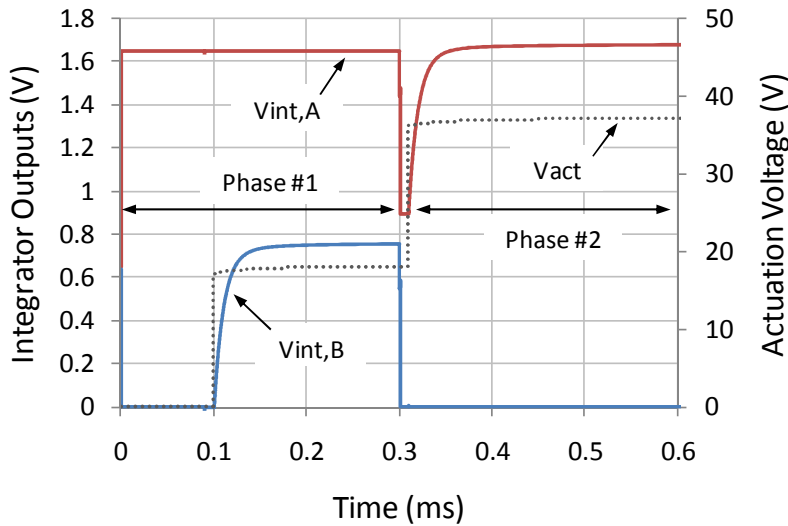

Figure 9. Simulation of the HV driver diagnosis sequence without MEMS.

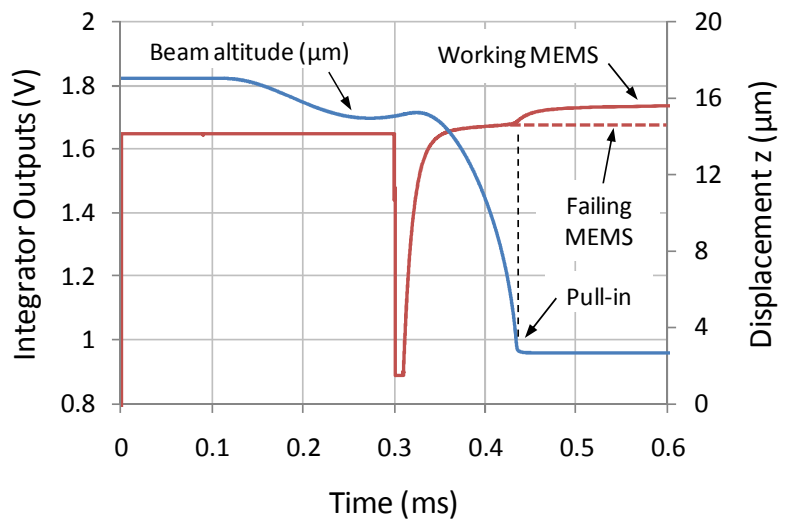

Figure 10. Simulation of the HV driver diagnosis sequence with working MEMS.

In Fig. 10, the simulation is performed with the electrostatic switch connected to the driver. The change in capacitance during the pull-in produces an increase of $\mathrm{V}_{\mathrm{int}, \mathrm{A}}$ of about $60 \mathrm{mV}$. According to Eq. (9), it corresponds to a change in capacitance of $\Delta C_{A c t}=770 \mathrm{fF}$. This value is in the range of expected change according to the model parameters reported in table I. The robustness of the approach against routing parameters $\left(\mathrm{R}_{\mathrm{ser}}, \mathrm{C}_{\mathrm{par}}\right)$ has been investigated with results reported in Fig. 11. It appears that for each case, the working MEMS produces a result well distinguishable from the result obtained with a broken switch. Note that the result strongly depends on the ability to set the correct $\mathrm{V}_{\mathrm{cc}}$ that produce a precise $\mathrm{V}_{\text {act }} / 2$. In this simulation, this $\mathrm{V}_{\mathrm{cc}}$ is set manually to $21 \mathrm{~V}$. Practically, this half-supply voltage can be generated onchip within a dedicated circuit that will address process variations and better separation between working and failing case is then expected. 


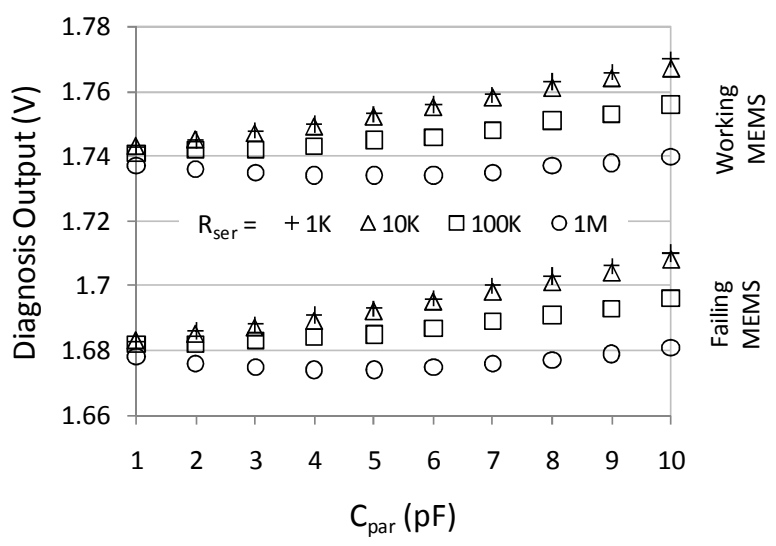

Figure 11. Comparison of diagnosis output for different routing parameters $\left(\mathrm{R}_{\mathrm{ser}}, \mathrm{C}_{\mathrm{par}}\right)$ with working and non-working MEMS.

\section{EXPERIMENTAL RESULTS}

A test chip including 18 driver channels has been fabricated using the High-Voltage $0.35 \mu \mathrm{m}$ CMOS technology from Austria Microsystems. The chip has been connected to both fixed capacitors and MEMS switches (Fig. 11).

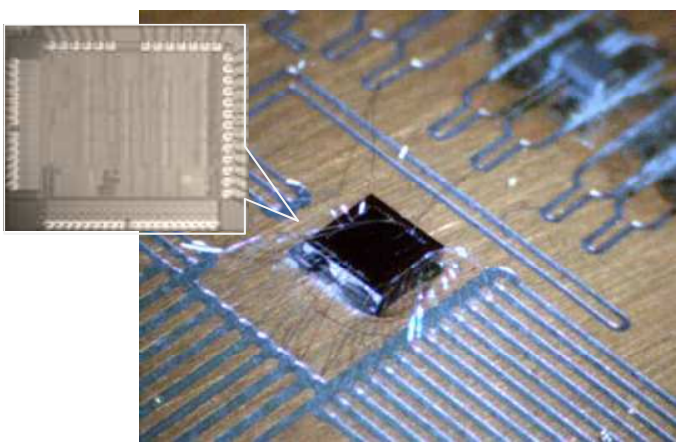

Figure 11. Custom PCB for the assembly of the test chip with fixed capacitors and MEMS switches.

First experiments have demonstrated that the driver part operates as specified with MEMS switches regarding actuation. For the characterization of the diagnosis function, fixed capacitors representing $\mathrm{C}_{\mathrm{par}}$ have been initially connected to the driver without MEMS. For three values of $\mathrm{C}_{\mathrm{par}}$, the diagnosis output $\left(\mathrm{V}_{\text {int, } \mathrm{A}}\right)$ voltage is presented in Fig. 12. The corresponding sensitivity is $3.6 \mathrm{mV} / \mathrm{pF}$, which is low enough to consider that the effect of $\mathrm{C}_{\mathrm{par}}$ is correctly rejected (rejection ratio is about 30 ).

Fig. 13 displays the output of the diagnosis circuit during a MEMS actuation. Qualitatively, the waveform is very similar to the one obtained by simulation (Fig. 10). An additional $25 \mathrm{mV}$ is brought across the integrator capacitor $\left(\mathrm{C}_{\text {int }}\right)$ during pull-in, corresponding to a $260 \mathrm{fF}$ change in the MEMS actuator capacitance.

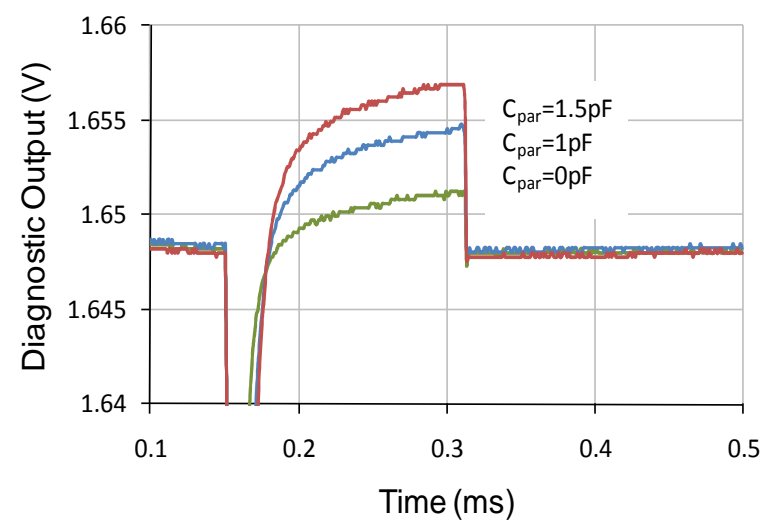

Figure 12. Measured diagnosis output voltage, for three values of Cpar, without MEMS

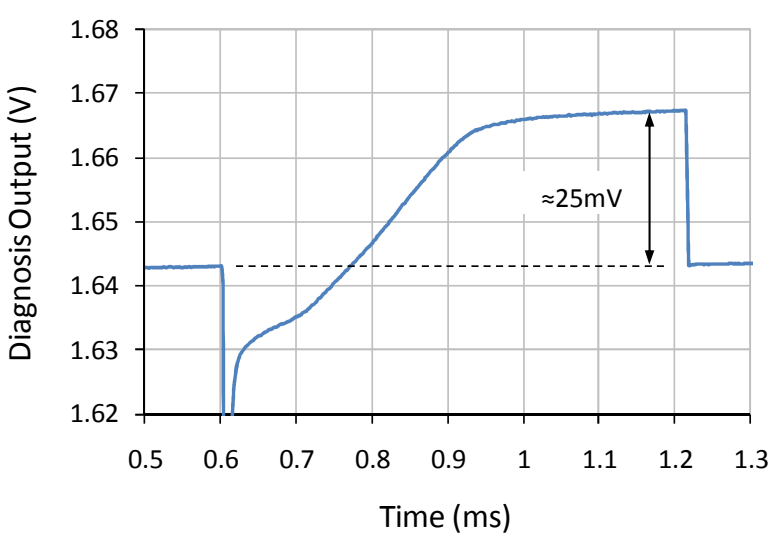

Figure 13. Measured diagnosis output voltage with a MEMS.

\section{CONCLUSION}

This paper introduces the design of High-Voltage drivers for MEMS electrostatic relays with diagnosis capability. The diagnosis is based on the measurement of the actuation current. A differential measurement technique that cancels the effect of serial resistance and parallel parasitic capacitance is proposed and validated by both simulations and experiments.

\section{ACKNOWLEDGMENT}

This work is supported by the French Ministry of Research in the framework of the ANR project (Agence Nationale de la Recherche) entitled "R3MEMS".

\section{REFERENCES}

[1] H. Salti, E. Fourn, R. Gillard, H. Legay, H. Aubert, "MEMS breakdown effects on the radiation of a MEMS based reconfigurable reflectarray", $3^{\text {rd }}$ European Conference on Antennas and Propagation (EuCAP'09), Berlin, 23-27 March 2009, pp. 3738 - 3741.

[2] B. Caillard, Y. Mita, Y. Fukuta, T. Shibata, and H. Fujita, “A highly simple failure detection method for electrostatic microactuators: application to automatic testing and accelerated lifetime estimation," IEEE Transactions on Semiconductor Manufacturing, vol. 19, no. 1, pp. 35-42, 2006.

[3] W. Merlijn van Spengen, R. Puers et. al., "Experimental Charaterization of Stiction Due to Charging in RF MEMS", International Electron Devices Meeting (IEDM), 2002, pp. 901-904.

[4] N. Dumas, L. Latorre, F. Mailly, P. Nouet, "Design of a Smart CMOS High-Voltage Driver for Electrostatic MEMS Switches", Design Test Integration \& Packaging of MEMS/MOEMS (DTIP'10), 5-7 May, Seville, Spain, 2010. 